\section{Recomendaciones sobre el uso de fluoruros para prevenir y controlar la caries dental en los Estados Unidos ${ }^{1}$}

Palabras clave: caries dental, fluoración, flúor, salud bucal.

\footnotetext{
Basado en el informe "Recommendations for using fluoride to prevent and control dental caries in the United States", elaborado por el Fluoride Recommendations Work Group a petición del Centro de Prevención y Control de Enfermedades (CDC) de los Estados Unidos de América. El informe, publicado originalmente en el número del 17 de agosto de 2001 de la revista Mortality and Morbidity Weekly Re-ports (MMWR 2001;50(RR14):1-42), está disponible a texto completo, en inglés, en http://www.cdc.gov/mmwr/preview/mmwrhtml/ rr5014a1.htm
}

La caries dental es una enfermedad infecciosa multifactorial que afecta a la mayoría de la población mundial. Los fluoruros reducen la incidencia de caries dental y reducen o revierten la progresión de las lesiones ya existentes. Los métodos más eficaces y más utilizados en la prevención y el control de la caries dental son los basados en la administración de fluoruros. Hoy día todos los residentes de los Estados Unidos (EE.UU.) están expuestos en alguna medida a los fluoruros, cuyo uso ha sido un factor esencial en la reducción de la prevalencia y gravedad de la caries dental en los EE.UU. y en otros países desarrollados. No obstante, la carga de la enfermedad sigue siendo considerable.

El fluoruro es la forma iónica del flúor. Los fluoruros poseen carga negativa, por lo que se combinan con los iones positivos. En el ser humano, la mayor parte del fluoruro está presente en los tejidos calcificados (huesos y dientes), debido precisamente a su gran afinidad por el calcio.

Los EE.UU. todavía no disponen de recomendaciones globales para la prevención y control de la caries dental, a pesar de que podrían reducir todavía más su prevalencia, así como la prevalencia de la fluorosis del esmalte y los gastos públicos y privados. En este informe se presentan recomendaciones globales para el uso de los fluoruros en la prevención y el control de la caries dental en los EE.UU. Aunque dichas recomendaciones fueron elaboradas específicamente para los EE.UU., algunos aspectos de este informe también podrían ser aplicables en otros países. Las recomendaciones fueron elaboradas por un grupo de trabajo de 11 especialistas convocados por los Centros de Prevención y Control de Enfermedades (CDC) de los EE.UU. a finales de los años noventa, y revisadas por un grupo de otros 23 especialistas. Sus objetivos consistieron en:

- servir de guía a los profesionales sanitarios y al público en general para el uso apropiado de los fluoruros

- dirigir la atención hacia la ingesta de fluoruros en menores de 6 años, con el fin de reducir el riesgo de fluorosis del esmalte

- proponer nuevos campos de investigación.

Este informe se centra en el análisis crítico de las pruebas científicas acerca de la eficacia y efecti- 
vidad de las diferentes formas de administración de fluoruros y en el uso de diferentes fuentes de fluoruros. No se aborda su seguridad, dado que ya ha sido ampliamente documentada por otras organizaciones científicas y de salud pública, como la Organización Mundial de la Salud.

\section{MECANISMOS DE ACCIÓN DE LOS FLUORUROS EN LA PREVENCIÓN Y CONTROL DE LA CARIES DENTAL}

La caries dental es una enfermedad infecciosa. Los productos bacterianos (ácidos, por ejemplo) disuelven el esmalte, atacan la dentina subyacente y acaban alcanzando los tejidos blandos de la pulpa. La caries dental puede ocasionar alteración de la estructura dentaria, dolor, pérdida de los dientes, e incluso infecciones sistémicas. Las bacterias cariógenas residen en la placa dental, una matriz orgánica adhesiva, formada por bacterias, y restos de coesmalte dental. Dichas bacterias producen polisacáridos que aumentan la adherencia de la placa al esmalte. Un paso inicial en la formación de la lesión consiste en el metabolismo de sustratos de la dieta, como los azúcares y otros hidratos de carbono fermentables. Los ácidos producidos por ese metabolismo desmineralizan el esmalte subyacente.

Los fluoruros presentes en la boca también son retenidos y concentrados en la placa dental y contribuyen de varias formas a controlar las lesiones iniciales de la caries dental. Los fluoruros concentrados en la placa dental y en la saliva inhiben la desmineralización del esmalte sano y estimulan su remineralización. A medida que las bacterias cariógenas metabolizan los hidratos de carbono y producen ácidos, la reducción del $\mathrm{pH}$ induce la liberación de fluoruros de la placa dental, los cuales, junto con los fluoruros de la saliva son captados con el calcio y el fosfato por el esmalte desmineralizado para mejorar su estructura y hacerlo más resistente a los ácidos. Los ciclos de desmineralización y remineralización continúan a lo largo de toda la vida de los dientes. Los fluoruros de la placa dental también inhiben el proceso mediante el cual las bacterias cariógenas metabolizan los hidratos de carbono para producir ácidos y alteran la producción bacteriana de polisacáridos adhesivos.

La concentración de fluoruros en la saliva ductal es tan baja $-0,006$ a 0,016 partes por millón (ppm), según se trate de zonas sin o con fluoración del agua potable - que probablemente no altere la actividad cariógena. Sin embargo, el consumo de agua fluorada, el uso de dentífricos fluorados y el uso de otros productos dentales fluorados puede multiplicar por 100 o 1000 la concentración de fluoruros en la saliva bucal. Dichas concentraciones vuelven a sus valores anteriores en 1 a 2 horas, pero durante este tiempo la saliva sirve como importante fuente de fluoruros que se concentran en la placa y remineralizan los dientes.

Inicialmente se pensó que los fluoruros solo beneficiaban a los niños, pues su acción se limitaría a los dientes preeruptivos, pero en la actualidad se sabe que también son beneficiosos para los adultos.

\section{RIESGO DE CARIES DENTAL}

La prevalencia y la gravedad de la caries dental en los EE.UU. han disminuido de forma sustancial en las tres últimas décadas, aunque dicha reducción no ha sido uniforme en toda la población y en la actualidad la carga de la enfermedad está concentrada en determinados grupos y personas. Para poner en marcha estrategias eficaces de prevención y control de la caries dental es fundamental identificar los grupos y las personas con mayor riesgo de presentar nuevas lesiones. Sin embargo, la determinación del riesgo de caries dental es difícil debido a la existencia de complejas interacciones entre múltiples factores.

Las poblaciones que parecen correr mayor riesgo de caries dental son las de bajo nivel socioeconómico o con padres de bajo nivel de educación, las que no reciben atención odontológica habitual y las que no poseen seguro médico con cobertura odontológica o no disponen de acceso a servicios odontológicos. Por otra parte, las personas pueden correr un alto riesgo de caries dental aunque no presenten ninguno de los factores anteriores. Los factores individuales que posiblemente aumenten el riesgo incluyen la caries dental activa, los antecedentes familiares de caries grave, la exposición de la superficie radicular debido a la retracción de las encías, los altos niveles de infección por bacterias cariógenas, el deterioro de la capacidad para mantener una buena higiene bucal, las malformaciones del esmalte o de la dentina, la disminución del flujo de saliva ocasionado por medicaciones, enfermedades o radioterapia, la baja capacidad de tamponamiento de la saliva y el uso de prótesis dentales o aparatos ortodóncicos. El riesgo puede aumentar cuando cualquiera de estos factores se combina con dietas cariógenas, como las dietas ricas en hidratos de carbono refinados, y disminuye con una buena exposición a los fluoruros.

El riesgo de caries dental cambia a lo largo del tiempo, a medida que cambian los factores de riesgo. Como la capacidad actual para predecir la caries dental es inexacta, en este estudio el riesgo se clasifica de forma dicotómica: alto o bajo. La mayoría de la población de los EE.UU. se clasificaría en la actualidad en el grupo de bajo riesgo. 
Los niños y los adultos con bajo riesgo de caries dental pueden mantener ese estado mediante la exposición frecuente a pequeñas cantidades de fluoruros, a través del consumo de agua fluorada o del uso de dentífricos fluorados. Los niños y adultos con alto riesgo de caries dental pueden beneficiarse de una mayor exposición a los fluoruros mediante el uso de colutorios, suplementos dietéticos o productos aplicados por profesionales. En caso de que la clasificación del riesgo sea dudosa, lo más prudente es considerar al individuo como si tuviera un alto riesgo hasta que se disponga de más información.

\section{RIESGO DE FLUOROSIS DEL ESMALTE}

La fluorosis del esmalte solo ocurre en menores de 8 años que ingieren cantidades excesivas de fluoruros durante períodos críticos del desarrollo de los dientes. La mayor susceptibilidad corresponde a las fases de transición y maduración temprana, que ocurren en diferentes momentos según el tipo de dientes (incisivos, caninos, etc.). Una vez completada la maduración preeruptiva, el esmalte deja de ser susceptible a la fluorosis. En los menores de 8 años, las fuentes de fluoruros son el agua potable, las bebidas y comidas procesadas, los dentífricos fluorados, los suplementos dietéticos que contienen fluoruros y otros productos dentarios. Este informe solo trata de la fluorosis del esmalte en menores de 6 años, porque después de esa edad solo son susceptibles los dientes más posteriores, difícilmente visibles. Incluso en sus formas más graves, la fluorosis del esmalte no tiene efectos funcionales adversos; sus efectos son exclusivamente cosméticos. En los EE.UU., los datos más recientes, procedentes de la Encuesta Nacional sobre la Caries Dental en Escolares de los EE.UU., 1986-1987 (National Survey of Dental Caries in U.S. School Children) indican que la prevalencia de la fluorosis del esmalte oscila entre el 22 y el $23 \%$. El cumplimiento de las recomendaciones de este informe acerca del uso apropiado de los fluoruros en menores de 6 años contribuirá a reducir la prevalencia y gravedad de la fluorosis del esmalte.

\section{FUENTES DE FLUORUROS Y SUS EFECTOS}

El agua potable fluorada y los dentífricos fluorados son las principales fuentes de fluoruros en los EE.UU., y a ellas se debe en gran medida el bajo riesgo de caries dental de la mayoría de los habitantes de este país. Las personas con alto riesgo de caries dental pueden necesitar una mayor exposición a los fluoruros y beneficiarse de otras formas de administración, como los colutorios, los suplementos dietéticos o los geles, espumas y barnices tópicos.

\section{Agua potable y comidas y bebidas procesadas fluoradas}

El agua potable fluorada contiene concentraciones de fluoruro, naturales o añadidas, eficaces para prevenir la caries dental. La ingesta de fluoruros en adultos estadounidenses y canadienses oscila entre $<1,0 \mathrm{mg} /$ día en zonas con aguas no fluoradas y 1 a $3 \mathrm{mg} /$ día en zonas con aguas fluoradas. En niños que residen en zonas con aguas fluoradas, la ingesta de fluoruros con la dieta es de unos 0,05 $\mathrm{mg} / \mathrm{kg} /$ día $(0,02$ a 0,10$)$; en los que residen en zonas con aguas no fluoradas, dicha cantidad es de aproximadamente la mitad. En los EE.UU., el agua y las bebidas procesadas pueden proporcionar cerca de un $75 \%$ de la ingesta de fluoruros.

Agua potable. Las actuales normas federales de fluoración del agua, mantenidas por el Servicio de Salud Pública de los EE.UU. desde 1962, establecen que el contenido de fluoruros del agua potable municipal debe ser de 0,7 a 1,2 ppm, dependiendo de la temperatura máxima media anual del aire. Los estudios iniciales sobre la fluoración del agua indicaron que la reducción de la caries dental infantil atribuible a la fluoración del agua era del 50 al 60\%. En estudios más recientes la cifra ha sido menor (18 a $40 \%$ ), probablemente debido al aumento del uso de otras fuentes de fluoruros, sobre todo los dentífricos fluorados. La fluoración del agua también reduce las disparidades entre los niños pobres y no pobres con respecto a la caries.

En algunas zonas donde no era factible la fluoración del agua potable municipal, se promovió durante muchos años la fluoración de los suministros de agua de las escuelas públicas. Como los niños solo están en la escuela parte del día, la concentración de fluoruros recomendada en estos casos era 4,5 veces mayor que la del agua municipal de la misma zona geográfica. Los estudios iniciales sobre los efectos de esta práctica indicaron que habría reducido en un $40 \%$ la incidencia de la caries dental entre los escolares, pero estudios más recientes indican que en la actualidad el efecto podría no ser tan pronunciado. Además, esta práctica se ha ido abandonando a partir de los años ochenta y se desconoce su difusión actual.

Algunas personas solo consumen agua embotellada y muchas aguas embotelladas contienen una cantidad de fluoruros $<0,3 \mathrm{ppm}$, lejos de la concentración óptima de 1,0ppm. 


\section{Recomendaciones}

\section{Salud pública y práctica clínica}

- Continuar y ampliar la fluoración del agua potable municipal. La fluoración del agua municipal es una forma segura, eficaz y barata de evitar la caries dental que beneficia a las personas de todos los grupos de edad y de todos los niveles socioeconómicos. Además es la forma de prevenir la caries dental que proporciona la mejor relación costo-efectivadad en comunidades con suministro municipal de aguas. En cambio, la utilidad de la fluoración de sistemas aislados de suministro de agua en las escuelas es más limitada, y la decisión de iniciar o continuar estos programas debería basarse en la valoración del riesgo de caries dental en cada escuela, en la disponibilidad de medidas preventivas alternativas y en la evaluación periódica de la eficacia del programa.

- Aconsejar a los padres y a los cuidadores sobre el uso de dentífricos fluorados por los niños pequeños, y en particular por los menores de 2 años. El uso de dentífricos fluorados es una forma de reducir la prevalencia de la caries dental que posee una buena relación costo-efectividad. Sin embargo, en los menores de 6 años, y en particular en los menores de 2 años, hay un riesgo considerable de fluorosis del esmalte que se puede reducir realizando dos o menos cepillados al día, aplicando una pequeña cantidad de pasta de dientes $(0,25 \mathrm{~g})$, supervisando el cepillado e instruyendo al niño para que escupa la pasta. En niños menores de 2 años, al sopesar los riesgos y beneficios del uso de dentífricos fluorados, el dentista y demás profesionales sanitarios deberían considerar la concentración de fluoruros en el agua potable municipal, otras fuentes de fluoruros y otros factores que puedan afectar a la susceptibilidad a la caries dental.

- Utilizar los colutorios fluorados únicamente en personas y grupos con alto riesgo de caries dental. Los niños menores de 6 años no deben usar colutorios fluorados sin consultar a un dentista o a otro profesional sanitario debido al riesgo de fluorosis del esmalte en caso de deglución repetida del colutorio.

- Prescribir suplementos de fluoruros de forma juiciosa. Estos suplementos se les pueden prescribir a los niños con alto riesgo de caries dental que consumen agua potable con bajas concentraciones de fluoruros, teniendo siempre en cuenta el riesgo de fluorosis del esmalte. La prescripción se puede hacer de forma individual o como parte de programas escolares dirigidos a todo un grupo.

- Aplicar productos con gran concentración de fluoruros a personas con alto riesgo de caries dental. Los productos con gran concentración de fluoruros pueden desempeñar un importante papel en la prevención y control de la caries dental en personas y grupos con alto riesgo de padecer la enfermedad. Al determinar la intensidad del tratamiento, los dentistas y otros profesionales sanitarios deben considerar la magnitud del riesgo y la edad del paciente. El uso rutinario de espumas o geles aplicados por profesionales proporcionan escasos beneficios en personas sin gran riesgo de caries dental, especialmente si consumen agua fluorada y usan dentífricos fluorados.

\section{Higiene personal}

- Conocer la concentración de fluoruros en la fuente primaria de agua potable. Todas las personas deberían saber si la concentración de fluoruros en su principal fuente de agua potable es subóptima, óptima o supraóptima, pues constituye la base para las decisiones personales y profesionales sobre la necesidad de utilizar otras modalidades de administración de fluoruros, como los colutorios o los suplementos.

- Usar frecuentemente pequeñas cantidades de fluoruros. Todas las personas deberían tener una frecuente exposición a pequeñas cantidades de fluoruros, lo cual se puede conseguir consumiendo agua con una concentración óptima de fluoruros y usando dentífricos fluorados dos veces al día.

- Supervisar el uso de dentífricos fluorados por los menores de 6 años. Los niños deben cepillarse los dientes diariamente, una vez que se haya producido su erupción. Antes de usar dentífricos fluorados en menores de 2 años se debería consultar al dentista. En menores de 6 años, para evitar la fluorosis del esmalte, el cepillado debe ser supervisado por un adulto, realizándose dos o menos veces al día, aplicando una pequeña cantidad de pasta de dientes $(0,25 \mathrm{~g})$ e instruyendo al niño para que escupa la pasta. 
- Considerar medidas adicionales en individuos con alto riesgo de caries dental. Las personas con alto riesgo de caries dental pueden necesitar fluoruros adicionales (uso diario de otros productos fluorados en el hogar o de productos tópicos fluorados aplicados por profesionales) $\mathrm{u}$ otras medidas preventivas (sellantes dentales o tratamientos antimicrobianos) para reducir la caries. A los menores de 6 años no se les deben proporcionar fluoruros adicionales sin consultar antes a un dentista o algún otro profesional sanitario.

- Usar fuentes alternativas de agua potable por los menores de 8 años cuya principal fuente de agua potable contiene una cantidad de fluoruros $>2$ ppm. Esta medida está destinada a reducir el alto riesgo de fluorosis del esmalte que corren estos niños. Cuando el agua municipal contiene $>2$ ppm pero $<4$ ppm, la Agencia de Protección Ambiental de los EE.UU. requiere que todos los hogares sean notificados anualmente de la necesidad de adoptar esta medida. Cuando el hogar consume agua de pozo es necesario determinar su concentración natural de fluoruros.

\section{Industrias y organismos sanitarios}

- Declarar el contenido de fluoruros en la etiqueta de las aguas embotelladas. Esto les permite a los consumidores tomar decisiones con conocimiento de causa y a los dentistas y otros profesionales sanitarios aconsejar a los pacientes sobre el consumo de fluoruros y el uso de productos fluorados.

- Promover el uso de pequeñas cantidades de dentífricos fluorados por los menores de 6 años. Los fabricantes deberían especificar en las etiquetas y publicidad de sus productos la necesidad de que estos niños usen una pequeña cantidad de pasta de dientes $(0,25 \mathrm{~g})$ en cada cepillado.

- Producir dentífricos con bajo contenido de fluoruros para los menores de 6 años. Estos productos "infantiles" deberían contener una cantidad de fluoruros que siga siendo eficaz para prevenir la caries dental, pero que al mismo tiempo reduzca el riesgo de fluorosis del esmalte.

- Colaborar en la educación de los profesionales sanitarios y del público. Las organizaciones de profesionales sanitarios, los organismos de salud pública y los fabricantes y distribuidores de productos dentales deberían colaborar en la educación de los profesionales sanitarios y del público en general acerca de las recomendaciones de este informe.

\section{Nuevas investigaciones}

- Realizar estudios metabólicos sobre los fluoruros. Se deben proseguir los estudios metabólicos en animales y humanos para determinar la influencia de las condiciones ambientales, fisiológicas y patológicas sobre la farmacocinética y los efectos de los fluoruros.

- Identificar marcadores biológicos de los fluoruros. La identificación de marcadores biológicos como alternativa a la medición directa de la ingesta de fluoruros podría llevar a mayor eficiencia en las investigaciones.

- Reevaluar el método de determinación de la concentración óptima de fluoruros en el agua potable municipal. Debido a los cambios ambientales que se han producido desde 1962, fecha de su adopción, se debería reevaluar el método actual, basado en la temperatura máxima media anual del aire. También es necesario investigar los actuales patrones de consumo de agua y de bebidas y comidas procesadas.

- Evaluar los efectos de los colutorios fluorados, de los suplementos de fluoruros y de otras modalidades de administración de fluoruros sobre la caries dental. Son necesarios nuevos ensayos clínicos para evaluar los efectos individuales y combinados de diferentes modalidades de administración de fluoruros, especialmente en individuos con alto riesgo de padecer la enfermedad, incluidos los mayores de 50 años.

- Estudiar la relación costo-efectividad de las actuales modalidades de administración de fluoruros. Las múltiples modalidades existentes en la actualidad y la baja prevalencia de la caries dental en los EE.UU. hacen necesaria la realización de estos estudios en poblaciones con diferentes riesgos de caries dental.

- Realizar estudios epidemiológicos descriptivos y analíticos. Su objetivo sería determinar la asociación entre la caries dental y la exposición a diferentes fuentes de fluoruros, así como el papel de la fluoración del agua potable municipal en la prevención de la caries coronal y radicular en adultos. Asimismo, es necesario perfeccionar los métodos de valoración del riesgo de caries dental.

- Identificar estrategias eficaces para promover la adopción de las recomendaciones actuales sobre el uso de fluoruros. Dichas estrategias deben estar dirigidas tanto a los adultos como a los niños, a sus padres y a los profesionales sanitarios. 


\section{Dentífricos fluorados}

En los años noventa, más del $90 \%$ de los dentífricos comercializados en los EE.UU., Canadá y otros países desarrollados eran fluorados. Como en muchos países no hay programas de fluoración del agua, los dentífricos podrían representar la principal fuente de fluoruros en todo el mundo. En estudios de 2 a 3 años de duración se ha observado que los dentífricos fluorados proporcionan una reducción mediana de la caries dental infantil del 15 al $30 \%$. Esta reducción es moderada en comparación con la proporcionada por el agua fluorada, pero hay que tener en cuenta que los estudios sobre la fluoración del agua generalmente han medido la exposición a lo largo de toda la vida, y no solo durante algunos años.

Hay pocos estudios sobre la eficacia de los dentífricos, colutorios, geles y barnices fluorados en poblaciones adultas. No obstante, los dientes siguen siendo susceptibles a la caries durante toda la vida y los fluoruros tópicos podrían ser eficaces para prevenir la caries en individuos de cualquier edad.

La mayoría de las personas se cepillan los dientes al menos una vez al día, pero una mayor frecuencia podría proporcionar mayor protección. La recomendación básica es dos cepillados al día y todavía no se sabe si tres cepillados al día permitirían reducir aun más la caries dental. Como la cantidad y vigor del enjuague tras el cepillado altera la concentración bucal de fluoruros, los mayores de 6 años podrían retener mayores cantidades de fluoruros en la boca si solo se la enjuagaran brevemente con una pequeña cantidad de agua o ni siquiera se la enjuagaran.

En los EE.UU., la concentración habitual de fluoruros en los dentífricos es de 1000 a 1100 ppm. En algunos estudios, los dentífricos que contienen 1500 ppm han sido más eficaces en la reducción de la caries y podrían ser beneficiosos para los mayores de 6 años con alto riesgo de caries dental.

Los niños que empiezan a usar dentífricos fluorados antes de los 2 años corren mayor riesgo de fluorosis del esmalte que los que empiezan a utilizarlos más tarde. Se ha demostrado que el uso de una pequeña cantidad $(0,25 \mathrm{~g})$ de dentífrico dos o menos veces al día reduce la importancia de los dentífricos fluorados como factor de riesgo de fluorosis del esmalte en menores de 6 años. La propensión de los niños pequeños a deglutir la pasta de dientes ha llevado a la producción de dentífricos "infantiles", con menores concentraciones de fluoruros. En ensayos clínicos se ha demostrado que los dentífricos que contienen $250 \mathrm{ppm}$ de fluoruros son menos eficaces en la prevención de la caries dental que aquellos que contienen $1000 \mathrm{ppm}$, pero los que contienen 500 a $550 \mathrm{ppm}$ son casi igual de eficaces en este aspecto y al mismo tiempo reducen considerablemente la prevalencia de fluorosis del esmalte.

El informe analiza también otras fuentes de fluoruros, como los colutorios fluorados, los suplementos dietéticos de fluoruros o los compuestos fluorados aplicados por profesionales (geles, espumas, barnices y pastas).

\section{CALIDAD DE LAS PRUEBAS SOBRE LA PREVENCIÓN Y EL CONTROL DE LA CARIES DENTAL}

El grupo de trabajo identificó las investigaciones publicadas y evaluó la calidad de las pruebas científicas sobre la capacidad de cada modalidad de administración de fluoruros para prevenir y controlar la caries dental. Para ello se revisaron las principales publicaciones científicas especializadas en inglés que disponen de un sistema de revisión por pares. La calidad de las pruebas científicas se clasificó en una escala ordinal de I (máxima calidad) a III.

Por la propia naturaleza de la intervención, los estudios sobre la fluoración del agua potable municipal no pueden ser aleatorizados ni doblemente enmascarados; en general, las pruebas proporcionadas por estos estudios son de grado II-1. Los estudios sobre la fluoración del agua de las escuelas tampoco han sido enmascarados ni controlados y han sido clasificados en el grado II-3. En cambio, los estudios sobre los dentífricos fluorados han sido aleatorizados, doblemente enmascarados, controlados con placebo y realizados siguiendo protocolos meticulosos (grado I). También se consideran de grado I las pruebas proporcionadas por los estudios sobre los colutorios, geles y barnices fluorados. Los estudios sobre los suplementos dietéticos de fluoruros han sido más heterogéneos y la calidad de las pruebas que han proporcionado oscila entre el grado I y el grado II-3.

\section{RELACIÓN COSTO-EFECTIVIDAD DE LAS DIFERENTES MODALIDADES DE ADMINISTRACIÓN DE LOS FLUORUROS}

La efectividad es uno de los principales requisitos de los servicios preventivos, pero también hay que considerar otros factores, entre ellos el costo. La información sobre la relación costo-efectividad de las diferentes modalidades de administración de fluoruros es bastante escasa. Si todos los demás factores se mantienen invariables, la relación costo- 
efectividad de cualquier modalidad será tanto mejor cuanto mayor sea el riesgo de caries dental. En individuos con bajo riesgo se obtendrán escasos beneficios con la adopción de medidas más allá de la fluoración del agua y al uso de dentífricos fluorados.

El costo medio anual estimado de la fluoración del agua municipal en los EE.UU. es de US\$ 0,72/persona $\left(0,17\right.$ a 7,62). ${ }^{2}$ Entre los factores que influyen sobre este costo per cápita se encuentran el tamaño de la comunidad (a mayor población menor costo); el número de puntos de inyección de los fluoruros en el sistema de suministro del agua; el tipo de alimentación del sistema y el equipo de monitorización utilizado; la cantidad y tipo del producto químico utilizado, su precio y el precio de su almacenamiento y transporte, y la experiencia del personal del sistema de distribución de agua. La fluoración del agua es una de las pocas medidas de salud pública que proporciona un verdadero ahorro de costos. Incluso en las condiciones más desfavorables, el costo medio de la fluoración del agua sería de US\$11 a \$17 por superficie cariada evitada, cifra muy inferior a los $\$ 65$ que costaría la restauración de una superficie cariada.

El costo de la fluoración del agua en las escuelas es similar al de la fluoración del agua en cualquier sistema público de suministro de agua a poblaciones de menos de 1000 habitantes: US\$ 6,37 por persona $(1,14$ a 13,69$)$. Su uso debe ser sopesado con cautela en las actuales condiciones de baja prevalencia general de la caries, de amplio uso de los dentífricos fluorados y de disponibilidad de otras modalidades de administración de fluoruros que se pueden utilizar en el ámbito escolar.

Los dentífricos fluorados no son más caros que los no fluorados. La utilización de unos $0,25 \mathrm{~g}$ de pasta dientes dos veces al día, suficiente para prevenir la caries, supone un costo anual de US\$ 6 a $\$ 12$, dependiendo de la marca, del tamaño del tubo y del lugar de compra. Por consiguiente, se puede considerar que los dentífricos fluorados constituyen una modalidad de prevención de la caries con una muy buena relación costo-efectividad.

El informe también proporciona datos sobre la relación costo-efectividad de los colutorios fluorados, de los suplementos dietéticos de fluoruros, de los productos fluorados aplicados por profesionales y de las combinaciones de diferentes modalidades de administración de fluoruros. Todas estas medidas pueden tener una buena relación costoefectividad en individuos con alto riesgo de caries dental, pero no como estrategia universal.

2 Todos los datos proporcionados aquí se expresan en dólares estadounidenses (US\$) de 1999.

\section{RECOMENDACIONES}

Al elaborar las recomendaciones formuladas en este informe, el grupo de trabajo tuvo en cuenta la calidad de las pruebas sobre los efectos de cada modalidad de administración de flururos en la caries dental y la fluorosis del esmalte, así como su relación costo-efectividad. Antes de promover el uso de una modalidad o de una combinación de modalidades, los profesionales sanitarios deben considerar el riesgo de caries dental de la persona o del grupo, el uso actual de otras fuentes de fluoruros y el riesgo de fluorosis del esmalte. Como el riesgo de caries dental puede variar a lo largo del tiempo, puede ser necesario modificar el tipo y frecuencia de las intervenciones preventivas en función de dichos cambios.

\section{CONCLUSIÓN}

Cuando se usan de forma adecuada, los fluoruros son un agente seguro y eficaz para la prevención y el control de la caries dental. Los fluoruros, necesarios durante toda la vida para evitar la caries, han contribuido de forma muy importante a mejorar la salud dental de la población de los EE.UU. y de otros países. Para mejorar todavía más la salud bucodental de la población es necesario seguir ampliando los programas de fluoración del agua potable y el uso de dentífricos fluorados. La adopción de las recomendaciones formuladas en este informe podría proporcionar considerables ahorros públicos y privados, sin comprometer los beneficios ofrecidos por los fluoruros.

\section{SYNOPSIS}

\section{Recommendations on the use of fluoride to prevent and control dental caries in the United States of America}

The widespread use of fluoride has been fundamental in reducing the prevalence and severity of dental caries in the United States of America and in other developed countries. When used appropriately, fluoride is safe and effective in preventing and controlling dental caries. Today, nearly all the residents of the United States are in some measure exposed to fluoride, which can come from multiple sources. This document is based on a report prepared by a working group assembled by the Centers for Disease Control and Prevention of the United States. The report details recommendations on fluoride use to prevent and control caries in the United States, but some aspects of the report could also be valid for other countries. Frequent exposure to small 
amounts of fluoride on a daily basis is the best way to reduce the risk of caries in all age groups. Therefore, it is recommended that all people drink water with an optimal fluoride concentration and that they brush their teeth twice a day with a fluoride toothpaste. Individuals with a high risk of caries may need additional fluoride sources. These recommendations attempt to provide dentists and other health professionals, public health professionals, and the general public with guidelines for fluoride use so that there is maximum protection against caries but without increasing the risk of enamel fluorosis, and with an efficient use of available resources. The recommendations are divided into four major groups: 1) public health and clinical practice, 2) self-care or individuals, 3) consumer-product industries and professional health care organizations and public health agencies, and 4) new research. Adopting these recommendations could reduce even further the prevalence of dental caries in the United States and save both public and private resources.

\section{Recibe el premio Soper un artículo de la Revista/Journal por investigadoras argentinas}

La Fundación Panamericana de Salud y Educación, entidad sin fines de lucro asociada con la Organización Panamericana de la Salud (OPS), otorgó el Premio Fred L. Soper de 2001 a dos investigadoras argentinas, Mariana Sanmartino y Liliana Crocco, por un artículo sobre la enfermedad de Chagas que se publicó en el número de marzo de 2000 de la Revista Panamericana de Salud Pública/Pan American Journal of Public Health. El Premio Fred L. Soper, otorgado por primera vez en 1990, se confiere por excelencia en el campo de la investigación y redacción en medicina y salud pública en la Región de las Américas. Sanmartino y Crocco fueron premiadas con un certificado y la suma de US\$ 2500.

Es primera vez que se lleva el Premio Soper un artículo publicado en la Revista/Journal, aunque dos que fueron publicados en el Boletín de la Oficina Sanitaria Panamericana, publicación precursora de a la Revista/Journal, ganaron el Premio Soper en 1997 y 1991.

El artículo de la Revista/Journal redactado por las dos investigadoras argentinas se titula "Conocimientos sobre la enfermedad de Chagas y factores de riesgo en comunidades epidemiológicamente diferentes de Argentina". Para fines del estudio, Sanmartino y Crocco encuestaron a personas en dos zonas rurales de Argentina con diferentes situaciones epidemiológicas. Las investigadoras evaluaron los conocimientos de esas personas sobre la enfermedad de Chagas, en particular su capacidad para identificar el insecto vector y su conocimiento de los mecanismos de transmisión. En el estudio se hallaron factores de riesgo relacionados con la construcción de las viviendas y un conocimiento inadecuado en torno a la enfermedad. A partir de estos datos las autoras concluyeron que un mayor conocimiento de la enfermedad de Chagas y de sus mecanismos de transmisión fortalecería la lucha contra la enfermedad y permitiría a los habitantes de zonas endémicas adoptar nuevos hábitos, reduciendo sus probabilidades de contraer la enfermedad.

Una copia del artículo de la Revista/Journal, que está escrito en español, se puede ver en el sitio Web de la OPS: http://www.paho.org

\section{Soper Award Goes to Revista/Journal Article by Argentine Researchers}

The Pan American Health and Education Foundation, a nonprofit partner of the Pan American Health Organization (PAHO), awarded the Fred L. Soper Award for 2001 to two Argentine researchers, Mariana Sanmartino and Liliana Crocco, for an article on Chagas' disease that appeared in the March 2000 issue of the Revista Panamericana de Salud Pública/Pan American Journal of Public Health. First granted in 1990, the Fred L. Soper Award recognizes excellence in medical and public health research and writing in the Region of the Americas. Sanmartino and Crocco received award certificates and a cash prize of US\$ 2500.

This is the first time that an article published in the Revista/Journal has won the Soper Award, but articles that were carried in the Boletín de la Oficina Sanitaria Panamericana, a predecessor of the Revista/Journal, won the Soper Award in 1997 and in 1991.

The Revista/Journal article by the two Argentine researchers was entitled "Conocimientos sobre la enfermedad de Chagas y factores de riesgo en comunidades epidemiológicamente diferentes de Argentina" (Knowledge about Chagas' disease and risk factors in Argentine communities with different epidemiological trends). For their study, Sanmartino and Crocco surveyed persons in two rural areas of Argentina with different epidemiological profiles. The researchers assessed those individuals' level of knowledge of Chagas' disease, including recognition of the insect vector and awareness of how the disease is transmitted. The study found risk factors related to the construction of houses as well as a limited understanding of the disease. Knowing more about the disease and how it is transmitted, the authors concluded, would help in the struggle against Chagas' disease and would empower the residents of endemic areas to adopt new habits and to reduce their likelihood of contracting the disease.

A copy of the Revista/Journal article, which is in Spanish, can be viewed for free on the PAHO Web site, at http://www.paho.org 